\title{
Study of the hydric behaviour of double-layered columns of unsaturated soils - Analysis of water and suction profiles during infiltration tests
}

\author{
Ibrahim Alimi Ichola ${ }^{1, a}$ and Laouni Gaidi ${ }^{2}$ \\ ${ }^{1}$ LGCIE, INSA-LYON, 69621 Villeurbanne, France \\ ${ }^{2}$ Faculté des Sciences et Technologie, Université de Mascara, Algérie
}

\begin{abstract}
Systems of sealing of containers or retention pounds are often associated to drainage layers for leachate recovery. The drainage layer can be installed either above the sealing layer or below it. In this paper, double layered columns of alluvia and clayey sand or of alluvia and clay are made up to run infiltration tests. A follow-up of the water content is implemented during the infiltration in multi-layer columns by using TDR probes. The values and changes in infiltration rate are different if the drainage layer is above or below the sealing layer. It is found that the drainage layer saturation is delayed when the sealing layer is above but the equilibrium water content remains the same for the both configuration. The electrical measurements in the drainage layers prove that the increase rate of the solute accumulation is the same for the both configuration and the same equilibrium solute concentration is reached. The measured coefficient of permeability of the double-layered becomes five times higher when the drainage layer is below the sealing layer. The position of the drainage layer influences the infiltration rate, the water and solute migration. The change in coefficient of permeability must be taken into account for the assessment of the flux of pollutant across a barrier system.
\end{abstract}

\section{Introduction}

The systems of sealing of containers or retention pounds are often associated with a drainage layer for leachate recovery. The drainage layer can be installed either above or under the sealing layer. The purpose of the tests carried out in this study is to observe the influence that the presence of the drainage layer has on the evolution of the hydrodynamic parameters of the sealing layer during the saturation process.

Columns made up either of a layer of alluvium and of clayey sand or of a layer of alluvium and of clay are prepared for the infiltration tests. The unsaturated soils are compacted in individual rings to ensure the homogeneity of the density of each layer of the doublelayered or the multi-layer one. Each layer is made up of one or more rings according to the final height of the column. A follow-up of the water content is implemented during infiltration by using TDR probes. The knowledge of the moisture characteristic curve of the soils and the use of the van Genuchten model, allows the layout of the profiles of suction. The results of the tests allow the comparison of the curves of infiltration of full-layer and multi-layered of unsaturated soil, to describe the profile forms in the double-layered ones and to compare the coefficients of permeability. By using TDR measurement of electrical conductivity, pollutant migration and retention is described.

\section{Experimental device and materials}

To study the hydric behaviour of multi-layer of unsaturated soils, soils of different geotechnical nature are associated in two or three layers. Tests of identification and compaction are carried out on each type of soil. These tests are supplemented by permeability tests on saturated soil to compare their resistance to the flow.

During the infiltration, the water content and impedance of soil in each layer are measured using TDR method. The infiltration head pressure is applied by using Mariotte burette.

\subsection{Geotechnical characteristic of tested soils}

The identification test results e.g. particle size distribution and Atterberg limits, indicate that the used soils are clayey sand (SC), clay and gravel (Gp). Standard permeability tests were performed on compacted soil at different dry unit weight $\gamma_{\mathrm{d}}$.

\footnotetext{
${ }^{\mathrm{a}}$ Corresponding author: ibrahimalimiichola8@msn.com
} 
Table 1. Soil geotechnical characteristics.

\begin{tabular}{|c|c|c|c|c|c|}
\hline Soils & $\begin{array}{c}\text { w (\%) } \\
\text { natural }\end{array}$ & LL & IP & $\begin{array}{c}\mathrm{w}_{\text {opt }} \\
(\%)\end{array}$ & $\left(\gamma_{\mathrm{d}} / \gamma_{\mathrm{w}}\right)_{\mathrm{opt}}$ \\
\hline $\begin{array}{c}\text { Clayey } \\
\text { sand }\end{array}$ & 12 & 30 & 19 & 12.5 & 1.85 \\
\hline Clay & 15.1 & 40 & 21 & 17.5 & 1.77 \\
\hline Alluvia & 6 & - & - & 6.5 & 2.06 \\
\hline
\end{tabular}

Table 1 presents the average values of the geotechnical parameters of the tested soils. Suction measurements on the three soils allow the determination of the moisture characteristic curves. The Van Genuchten model (Fig. 1), is used to describe the measured points. Table 2 presents the values of the parameters defining the model by fitting the experimental measured points.

$$
\theta(\psi)=\theta_{r}+\frac{\theta_{s}-\theta_{r}}{\left(1+(\alpha \psi)^{n}\right)^{m}}
$$

$\theta$ volumetric water content, $\psi$ suction potential

$\theta_{r}$ residual water content, $\theta_{s}$ equilibrium water content

The model formulas are used to compute the suction potential profiles from water content profiles.

Table 2. Parameters of van Genuchten model.

\begin{tabular}{|c|c|c|c|c|c|}
\hline Soils & $\begin{array}{c}\theta \mathrm{r} \\
\left(\mathrm{m}^{3} / \mathrm{m}^{3}\right)\end{array}$ & $\begin{array}{c}\theta \mathrm{s} \\
\left(\mathrm{m}^{3} / \mathrm{m}^{3}\right)\end{array}$ & $\alpha\left(\mathrm{cm}^{-1}\right)$ & $\mathrm{m}$ & $\mathrm{n}$ \\
\hline $\begin{array}{c}\text { Clayey } \\
\text { sand }\end{array}$ & 0.024 & 0.403 & 0.01 & 0.28 & 1.389 \\
\hline Clay & 0.125 & 0.42 & 0.003 & 0.25 & 1.333 \\
\hline Alluvia & 0.024 & 0.29 & 0.0012 & 1.97 & 0.864 \\
\hline
\end{tabular}

\subsection{Methods and test devices}

The infiltration tests are carried out on columns made up of several rings. The soils are compacted in each ring with the chosen dry density and water content. Each ring is equipped with a TDR probe of three rods of $81 \mathrm{~mm}$ of length. The rings used have a diameter of $106 \mathrm{~mm}$ and of $50 \mathrm{~mm}$ height. The diagram of the assembly in column is presented in Figure 1. Because of the duration of test, only three rings are used for the column made up of clay and alluvia. In the assembly of the column into multilayer, the layer having the lowest permeability represents the barrier layer. When the bed of clay or GCL (Geotextile Clay Liner) represents the barrier, a layer of alluvia is installed on both sides of the sealing layer.

Table 3. Initial conditions of soils in layered column.

\begin{tabular}{|c|c|c|c|c|}
\hline Soils & $\mathrm{w}_{\mathrm{i}} \%$ & $\gamma_{\mathrm{d}} / \gamma_{\mathrm{w}}$ & $\begin{array}{c}\text { height } \\
(\mathrm{cm})\end{array}$ & $\begin{array}{c}\text { head } \\
\text { pressure }(\mathrm{cm})\end{array}$ \\
\hline $\begin{array}{c}\text { Clayey } \\
\text { sand }\end{array}$ & 6.5 & 2.04 & 35 & 10 \\
\hline Clay & 9.3 & 1.6 & 20 & 10 \\
\hline Alluvia & 20 & 1.66 & 20 & 10 \\
\hline
\end{tabular}

When one studies the hydric behaviour of double- layered soil, the influence of the position of the layer of drainage onto the sealing layer is examined. The initial conditions of the tests are presented in the table 3 .

TDR waveforms are produced by cable tester Tektronix 1502C (OR) and collected on computer using our own signal acquisition program. Further analysis of the collected TDR waveforms allows the determination of the dielectric constant of the soil. Using the relationship proposed by Topp et al.[7], the volumetric water profiles are determined for each multi-layer column. Applying the formula of van Genuchten of each soil, the profiles of the suction potential are computed.

The coefficient of permeability of the multi-layer is determined using the outflow rate.

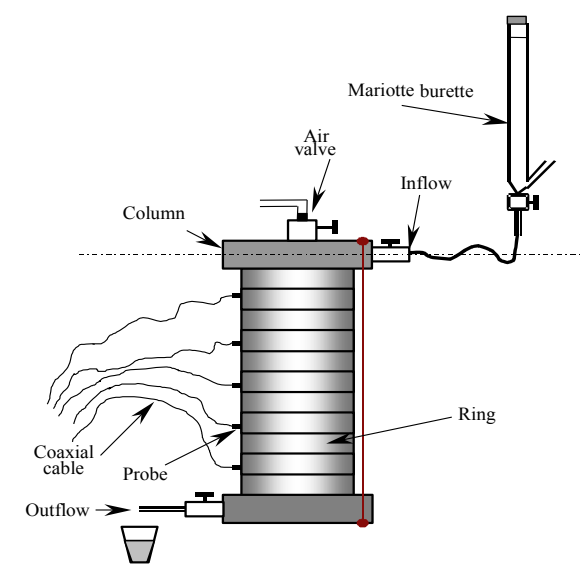

Figure 1. Schematic of soil column used for infiltration tests

\section{Experimental results}

To highlight the hydric behaviour of the unsaturated multi-layer soil, the measurement results are used to compute the water content profiles, the electrical conductivity profiles and that of the water potential during moisture movement. The infiltration rate is used to observe the influence of the drainage layer above or below the sealing layer. When the percolated outflow occurs, the coefficient of permeability of the multi-layer soil is computed. The electrical conductivity profiles computed from soil impedance, allow the description of the pollutant movement.

\subsection{Description of the infiltration rate in multi- layer}

To investigate the difference in infiltration rate in layered soils, three columns are built up with alluvia on clayey sand, alluvia below the clayey sand and clayey sand only. The three columns have the same height. A $10 \mathrm{~cm}$ head pressure is used to launch the infiltration.

Three types of rate are used to describe the water inflow in the three columns. The rate $v_{i}$ is determined at early time of the infiltration. It is called initial rate of infiltration. The second rate used $\mathrm{v}_{0}$ is defined when the steady flow is reached and the third rate $\mathrm{v}_{\mathrm{s}}$ is computed when the water outflows the column.

The values of these different rates are presented in the table 4 . 
Table 4. Different rates characterising the infiltration in layered columns.

\begin{tabular}{|c|c|c|c|}
\hline & $\begin{array}{c}\text { Column 1 } \\
\text { Clayey } \\
\text { sand }\end{array}$ & $\begin{array}{c}\text { Column 2 } \\
\text { Alluvia } \\
\text { on clayey } \\
\text { sand }\end{array}$ & $\begin{array}{c}\text { Column 3 } \\
\text { Alluvia } \\
\text { under } \\
\text { clayey sand }\end{array}$ \\
\hline $\begin{array}{c}\text { Rate } \mathrm{v}_{0} \\
(\mathrm{~m} / \mathrm{s})\end{array}$ & $3.3610^{-6}$ & $5.6310^{-6}$ & $1.3310^{-5}$ \\
\hline $\begin{array}{c}\text { Rate } \mathrm{v}_{\mathrm{i}} \\
(\mathrm{m} / \mathrm{s})\end{array}$ & $3.6710^{-5}$ & $5.5510^{-5}$ & $4.2610^{-5}$ \\
\hline $\begin{array}{c}\text { Rate } \mathrm{v}_{\mathrm{s}} \\
(\mathrm{m} / \mathrm{s})\end{array}$ & $5.1010^{-6}$ & $9.610^{-6}$ & $1.6310^{-5}$ \\
\hline
\end{tabular}

It is observed that the steady infiltration is reached more quickly in multi-layer alluvia-clayey sand; in 2hours when 4 hours are needed for clayey sand column. It is shown in Table 4 that the steady rate is higher during the infiltration test on the multi-layer columns. It is also found that this rate increases when the drainage layer is located below the sealing layer. However, the initial infiltration rates in the three columns are slightly different. The outflow rates are also higher for the multilayer columns. This rate is larger when the drainage layer is below the sealing layer.

\subsection{Influence of the multi-layer on the soil permeability}

Figure 2 presents the trends of the hydraulic conductivity during the process of saturation of the three columns. It is found that the hydraulic conductivity function decreases during the columns saturation and the values remain higher when the drainage layer is under the sealing layer. The position the different curves of the hydraulic conductivity function proves that the sealing trends are better when there is no drainage layer and it is relevant to install the drainage layer over the sealing layer.

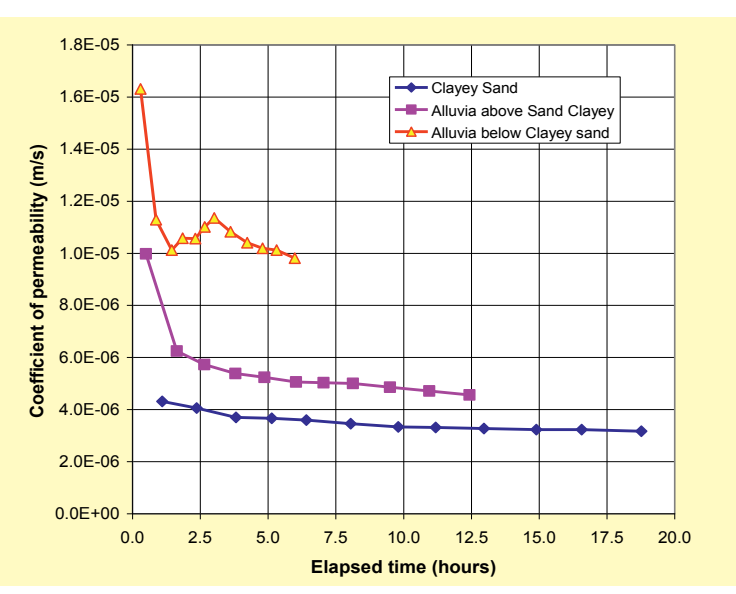

Figure 2. Comparison of permeability coefficient of the three columns

Determined by the standard permeability test, the range of the coefficient of permeability of alluvia layer is $2.10^{-5}$ $\mathrm{m} / \mathrm{s}$. That of clayey sand layer is $3.310^{-6} \mathrm{~m} / \mathrm{s}$.

The equivalent permeability $k_{e q}$ of the two layers alluvia - clayey sand can be computed by the following formula:

$$
k_{e q}=\frac{\sum_{i} L_{i}}{\sum_{i} \frac{L_{i}}{k_{i}}}
$$

$L_{i}$ thickness of each layer

$k_{i}$ permeability coefficient of each layer

Table 5. Comparison of calculated equivalent permeability of multi-layer and measured coefficient.

\begin{tabular}{|c|c|c|}
\hline $\begin{array}{c}\text { Equivalent } \\
\text { permeability }\end{array}$ & $\begin{array}{l}\text { Alluvia on clayey } \\
\text { sand }\end{array}$ & $\begin{array}{c}\text { Alluvia under } \\
\text { clayey sand }\end{array}$ \\
\hline & $20 \mathrm{~cm} \underset{ }{25 \mathrm{~cm}}$ & $35 \mathrm{~cm}$ \\
\hline $\begin{array}{c}\text { Measured } \\
(\mathrm{m} / \mathrm{s})\end{array}$ & $5.010^{-6}$ & $1.010^{-5}$ \\
\hline $\begin{array}{l}\text { Calculated } \\
(\mathrm{m} / \mathrm{s})\end{array}$ & $4.7510^{-6}$ & $4.7510^{-6}$ \\
\hline
\end{tabular}

In table 5 are presented the values of measured and calculated equivalent permeability of double layers soils of different permeability. The formula (2) does not take into account the position of the drainage layer, whereas it is found that the measured value is different according its position. So it is noticed that the drainage layer changes the permeability of the sealing layer and its position also. In this sealing system, the hydraulic conductivity increases. To improve the sealing action, it is better to install the drainage layer above the sealing layer. To complete the hydraulic behaviour of the sealing system, the profiles of water and suction must be examined.

\subsection{Description of water content profiles during multi-layer saturation}

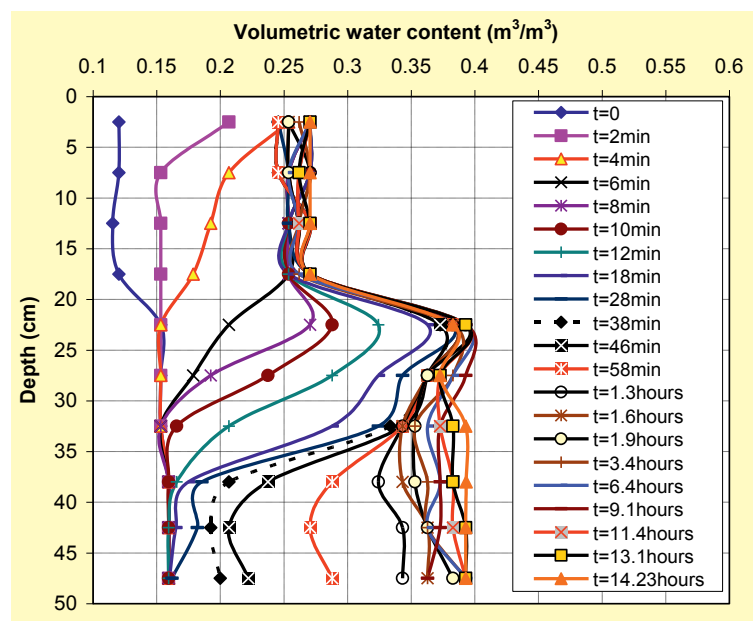

Figure 3. Water content profiles: Alluvia above clayey sand 


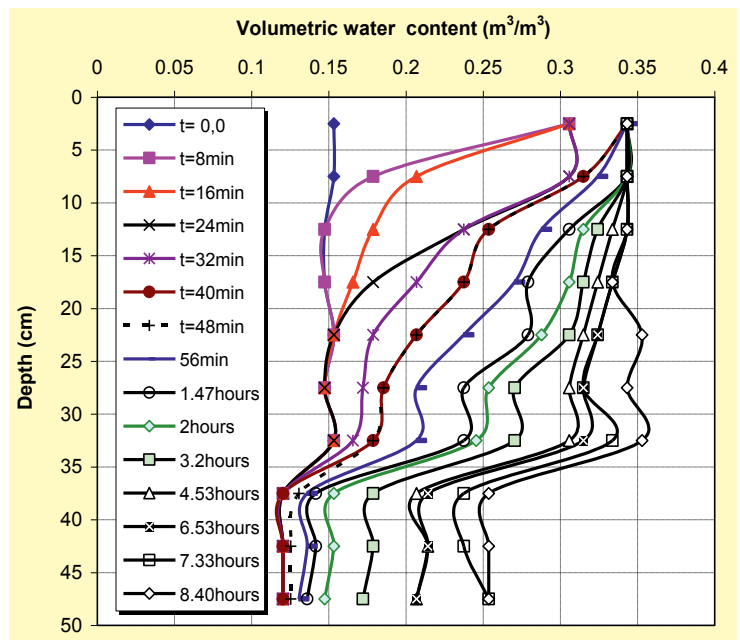

Figure 4. Water content profiles: Alluvia below clayey sand

Figures 3 and 4 present the profiles monitored during the saturation of a double layered soil. The profile corresponding to water outflow is indicated by dot curve. When the alluvia layer is above the sealing layer, the saturation is reached in 10 minutes and the water outflow begins after 38 minutes of infiltration. The value of the water content of alluvia layer remains small $\left(0.125 \mathrm{~m}^{3} / \mathrm{m}^{3}\right)$, during the water outflow when the drainage layer is below the sealing layer. The sealing layer delays the saturation of the drainage layer which is not reached before the water outflows. That is why the outflow rate increases and increases the permeability of the sealing system. It is noticed that sealing layer saturation is also delayed when it is above the drainage layer (Fig. 4). The value of the water content reached in the sealing layer at the saturation state is less when the sealing layer is above the drainage layer $\left(0.35 \mathrm{~m}^{3} / \mathrm{m}^{3}\right.$ instead of $0.40 \mathrm{~m}^{3} / \mathrm{m}^{3}$ ). So above the sealing layer, the drainage layer favours its saturation. In the single column of clayey sand, the equilibrium water content reached is $0.36 \mathrm{~m}^{3} / \mathrm{m}^{3}$, value which is related to gravity effect.

\subsection{Description of suction profiles during multi- layer saturation}

To describe water potential evolution in the double layered soil, during saturation process, the function (3) is used [6]. Suction potential profiles computed from water content profiles are presented in figures 5 and 6 .

$\mathrm{Se}=\frac{\theta-\theta_{\mathrm{r}}}{\theta_{\mathrm{s}}-\theta_{\mathrm{r}}}=\left[\frac{1}{1+(\alpha|h|)^{\mathrm{n}}}\right]^{\mathrm{m}}$ if $h<0$

$$
\mathrm{Se}=1 \quad \text { if } h \geq 0
$$

where, $\theta_{r}$ : residual volumetric water content

$\theta_{s}$ : saturated volumetric water content $(h=0)$

$\alpha, \mathrm{n}$ and $\mathrm{m}$ : parameters of the model

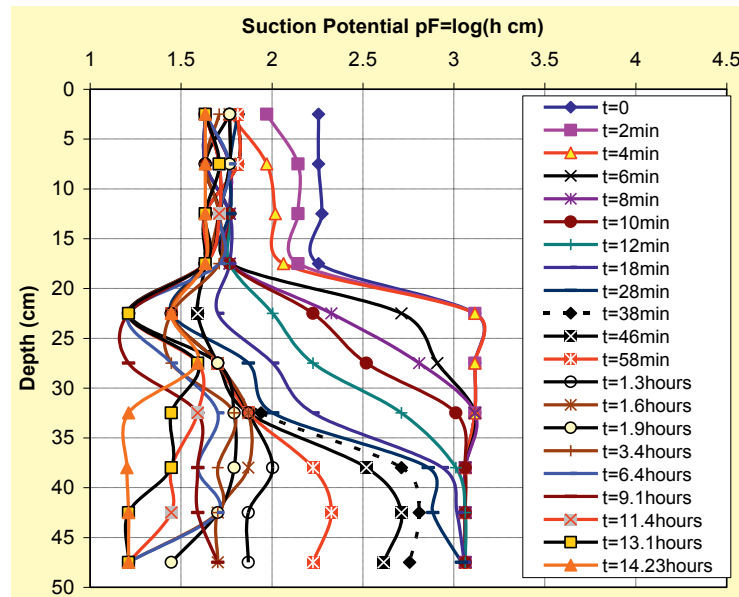

Figure 5. Suction profiles: Alluvia above clayey sand

When the alluvia layer is above the clayey sand layer, water potential value at saturation is reached in 8 minutes. So only a convective flow in the drainage layer provides water in the sealing layer. The drainage layer behaves like a reservoir providing water in the sealing layer. It is noticed that the water potential remains high in bottom of the double layered column $(\mathrm{pF} 2.75,56 \mathrm{kPa})$, when the outflow begins (Fig. 5). This high retention pressure allows a better saturation of the sealing layer reducing the outflow volume.

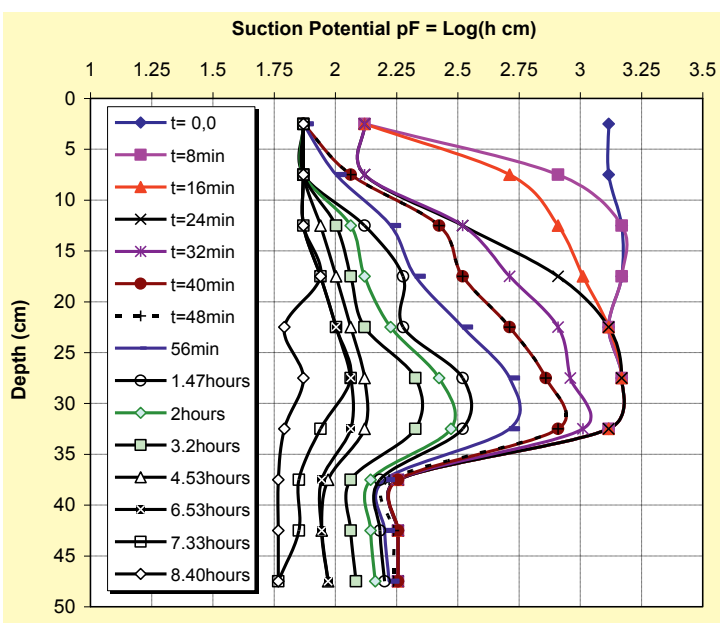

Figure 6. Suction profiles: Alluvia below clayey sand

The retention pressure at the bottom of the double layered soil column remains also high $(\mathrm{pF} 2.24,17 \mathrm{kPa})$ when water outflows from the drainage layer below the sealing layer. The value of the retention pressure in the drainage layer remains two hours with little change whereas it decreases quickly in the sealing layer. The gravity flow prevents the accumulation of water in the drainage layer. This explains the high outflow rate when the drainage layer is below the sealing layer.

It is noticed that the value of the equilibrium water content in the drainage layer is nearly the same whatever its position. It is found nearly the same value of the equilibrium suction in the double layered column when the drainage layer is below the sealing layer. This means that the drainage layer controls the water flow inside the column by its position. 


\subsection{Description of the double layered soil as pollutant barrier}

To describe the flow of polluted water and the retention of pollutant in double layered soil, lead slag leachate is percolated through the soil column. The used lead slag leachate is an acid leachate (pH6.3) with an electrical conductivity of $53 \mathrm{mS} / \mathrm{cm}$. Meddahi et al. [4] have proved that the TDR measurements can be used to obtain the breakthrough curves of non-reactive solute. So, supposing a linear relation between the soil electrical conductivity and the concentration of the soil pore water, it is shown that relation between the solute mass and the soil electrical conductivity is linear [3]. So the transfer of the solute in the soil during infiltration tests can be followed by monitoring the electrical conductivity of the soil.

Electrical conductivity measurement by the TDR method is described by Nader et al. [5]. Using the geometric constant of the TDR probes and the measured soil impedance profiles, electrical conductivity profiles and the breakthrough curves of the solute can be computed [1].

\subsubsection{Description of solute retention in the double layered soil by electrical conductivity}

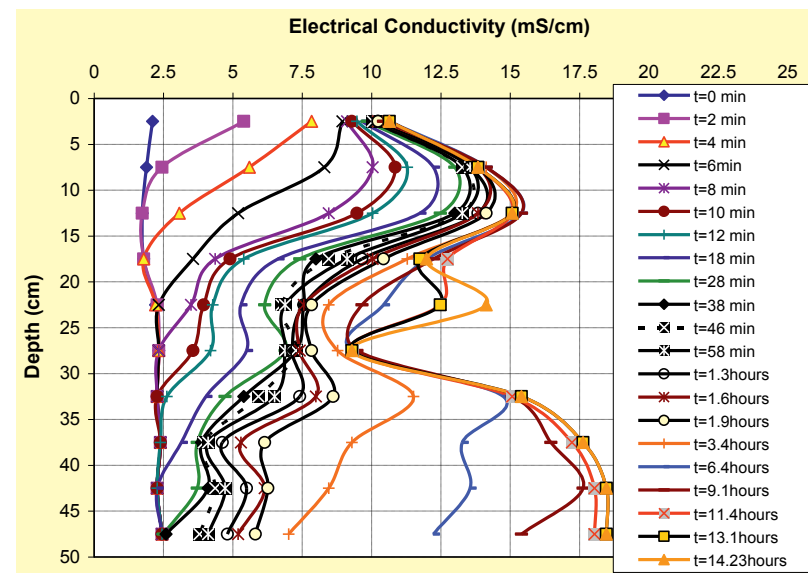

Figure 7. Electrical conductivity profiles: Alluvia above clayey sand

The changing profiles of electrical conductivity provide an input on the retention of the solute in the soil. When the alluvia layer is above the sealing layer (Fig. 7), the last value of the electrical conductivity remains at $10 \mathrm{mS} / \mathrm{cm}$ and $15 \mathrm{mS} / \mathrm{cm}$ respectively on the top and bottom of the drainage layer. The values decrease at the entrance of the clayey sand layer proving that the leachate is depleted by flowing in depth. While the equilibrium water content is practically achieved by 6 minutes, the electrical conductivity decreases in the thickness of the drainage layer before the equilibrium value is reached. The shape of the profiles in the drainage layer shows that the solute diffuses in depth during the first 8 minutes of infiltration. This solute transfer mode is also observed in the sealing layer to the release of the leachate. Then the transfer of the solute in the clayey sand is a convective transfer and the solute accumulation at the bottom of the column after 1.9 hours of infiltration, accelerates.

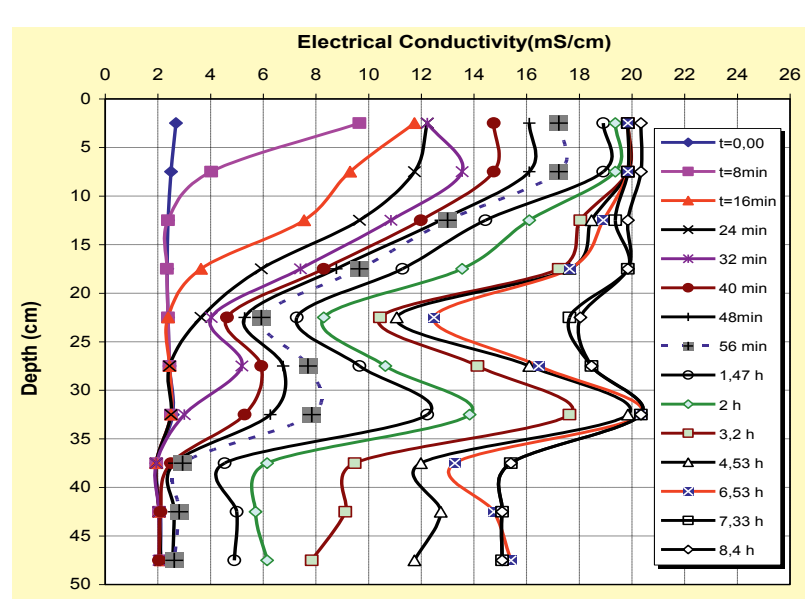

Figure 8. Electrical conductivity profiles: Alluvia below clayey sand

When the alluvia layer is below the sealing layer, the solute transfer begins in the clayey sand layer by diffusion and after 24 minutes of infiltration, convectivediffusive transfer is observed. Solute accumulation is noticed at the bottom of the sealing layer after the leachate begins to flow out. The electrical conductivity reaches $20 \mathrm{mS} / \mathrm{cm}$ when it does not exceed an equilibrium value of $18.5 \mathrm{mS} / \mathrm{cm}$ when the drainage layer is above. The solute transfer in the drainage layer begins with the leachate outflow in convective mode and reaches equilibrium value of $15 \mathrm{mS} / \mathrm{cm}$.

The position of the drainage layer changes both the transfer mode of the solute in the sealing layer, the retention capacity of the two layers and the time required for the output of the leachate from the double layered column.

Gaidi and Alimi-Ichola [2] have computed a relationship between leachate solute concentration and leachate electrical conductivity. The equation (4) gives the scaled value of the solute concentration $\left(F S / F S_{0}\right)$ when the scaled value of the electrical conductivity of the leachate $\left(\sigma / \sigma_{0}\right)$ is measured. $F S_{0}$ is the initial solute concentration in the leachate and $\sigma_{0}$ its electrical conductivity. Measuring the electrical conductivity of the leachate during the percolation of the barrier system, the change in leachate concentration is computed using the relationship (4).

$$
\begin{aligned}
& \frac{F S}{F S_{0}}=5.3747\left(\frac{\sigma}{\sigma_{0}}\right)^{4}-8.8419\left(\frac{\sigma}{\sigma_{0}}\right)^{3} \\
& +4.1908\left(\frac{\sigma}{\sigma_{0}}\right)^{2}+0.4095\left(\frac{\sigma}{\sigma_{0}}\right)-0.0159
\end{aligned}
$$

Using relationship (4), it is noticed that the maximum solute concentration retained in the drainage layer is $27 \%$ of solute contained in the leachate, whatever its position. The proportion of the solute retained in the clayey sand layer reaches $37 \%$ when the drainage layer is below and $34 \%$ when it is above. 


\subsubsection{Description of solute breakthrough curves}

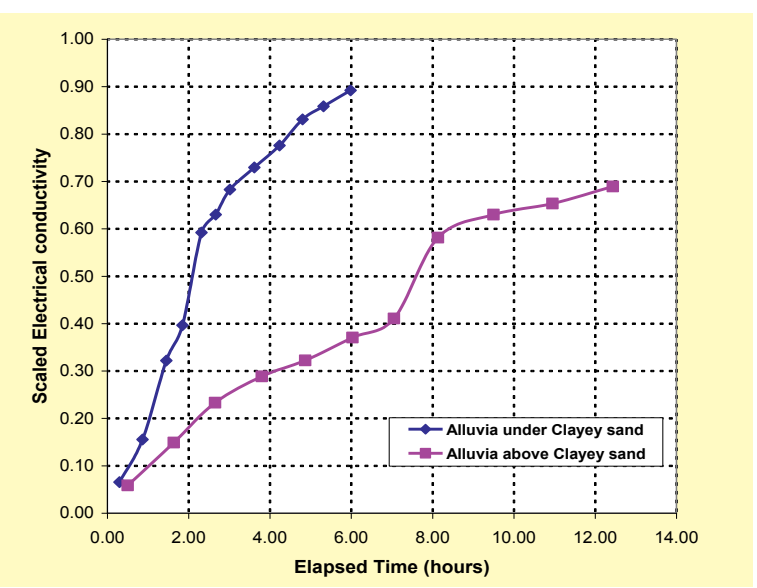

Figure 9. Breakthrough curves during leachate outflow described by the electrical conductivity

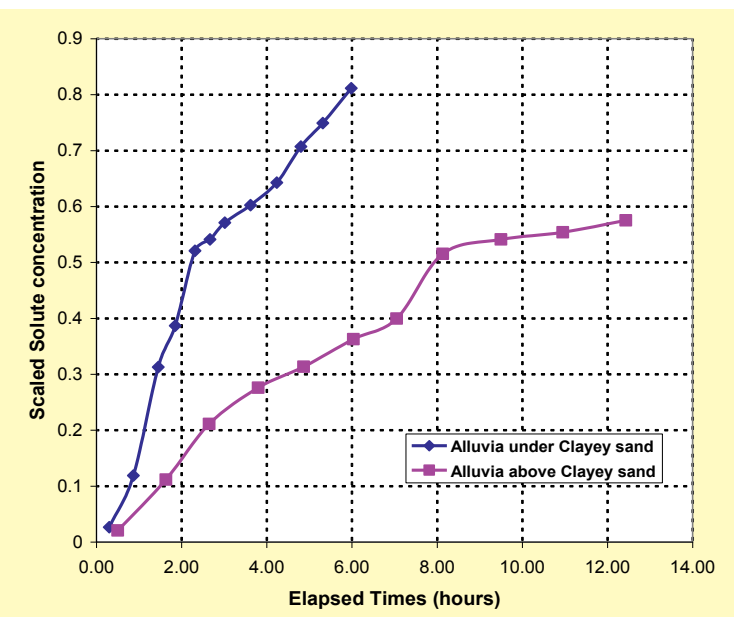

Figure 10. Breakthrough curves during leachate outflow (Solute)

Figures 9 and 10 present the breakthrough curves described by the electrical conductivity and computed by relation (4). The proportion of solute in output leachate is greater when the drainage layer is below the sealing layer. After recovering a volume of leachate equal to 1.8 volumes of the pores of the soil in the column, $70 \%$ of solute outflows when the drainage layer is above. Then $80 \%$ of solute concentration is reached when the drainage layer is below after 1.2 volumes of the pores is recovered. The sealing system is a better pollutant barrier when the drainage layer is above. Its performance is provided by the delay it imposes on the outflow of the pollutant.

\section{Conclusion}

The fight against flooding or groundwater pollution involves the setting up of basins fitted either for infiltration or to prevent pollution. The infiltration system or the sealing system, made up of natural materials, is unsaturated soil layer. The study shows that the hydric behaviour of samples soil layer composed of layers of different permeability is not only described by the equivalent permeability coefficient. The liquid flow through the multi-layer sample depends on the arrangement of the layers of different permeability within it. A layer of high permeability above a layer of low permeability slows down the flow. This appears in infiltration ponds, zones of permeability, described as restricted zones which promote clogging of soil surface. But to ensure the performance of a sealing layer, it is better to install the drainage layer on the low permeability layer.

The delay of the water propagation in a multi-layer is explained by the rapid decrease of the potential value of suction during saturation, when the drainage layer is below.

The transfer of solute from the leachate to the soil is also influenced by the superposition layers of different permeability coefficient. By continuous infiltration of leachate with constant solute concentration, through the multi-layer, it is found that the retention capacity depends on the position of the layer having the higher permeability coefficient. Solute retention is better if this layer is placed below the barrier layer. It is noted that the outflow of the solute is faster when the drainage layer is below and the multi-layer quickly reaches its retention capacity. The change in the coefficient of permeability must be taken into account for the assessment of the flux of pollutant across a barrier system.

\section{References}

1. I. Alimi-Ichola, Use of Time Domain Reflectrometry probes for monitoring unsaturated soil pollution. Environmental Geotechnics. Proc. 3rd Int. Cong. Lisboa, Portugal, Sept. 1998, 107-112 (1998)

2. L. Gaidi, I. Alimi Ichola, Utilisation des sondes TDR pour estimer la masse de soluté retenue par une couche d'argile lors d'une infiltration (Bull. Eng. Geol. Env 62:47-56) (2003)

3. R.G. Kachanoski, E. Pringle, A.L. Ward, Field Measurement of solute Travel Times using Time Domain Reflectrometry, Soil Sci. J., vol. 56, 47-52 (1992)

4. M.E. Meddahi, D. Mallants, J. Feyen, M. Badji, H. Vereecken, Paramètres essentiels d'écoulement des solutés dans un milieu poreux saturé : Méthode de mesure et modèle d'interprétation, Science du sol, 31, (4), 233-250 (1993)

5. A. Nader, S. Dasberg, I. Lapid, Time Domain Reflectrometry Measurement of water content and electrical conductivity of layered soil column, Soil Sci. Am. J. 55 938-943 (1991)

6. M.Th. Van Genuchten, A closed-form equation for predicting the hydraulic conductivity of unsaturated soils, Soil Science of America Journal, vol. 44, pp. 892-898 (1980)

7. G. C. TOPP, J. L. DAVIS, and A. P. ANNAN, Electromagnetic Determination of Soil Water Content: Measurement in Coaxial Transmission Lines. Water Resour. Res. 16:574-582 (1980) 